\title{
Removal of Alkylphenols from Industrial and Municipal Wastewater
}

\author{
J. Derco, ${ }^{\mathrm{a},{ }^{*}}$ J. Dudáš, ${ }^{\mathrm{a}}$ M. Valičková, ${ }^{\mathrm{a}}$ L. Sumegová, ${ }^{\mathrm{a}}$ and S. Murínováb \\ anstitute of Chemical and Environmental Engineering, Faculty of \\ Chemical and Food Technology, Slovak University of Technology, \\ Radlinského 9, 81237 Bratislava, Slovak Republic \\ bWater Research Institute, Nábrežie L. Svobodu 5, \\ 81249 Bratislava, Slovak Republic
}

doi: 10.15255/CABEQ.2016.1021

Original scientific paper

Received: October 19, 2016

Accepted: June 13, 2017

\begin{abstract}
The results of the study of removal of nonylphenol, octylphenol and their ethoxylates from real industrial and municipal wastewater are presented. Industrial wastewater was pre-treated by coagulation with $\mathrm{FeCl}_{3}$ and adsorption on zeolite, before discharging into municipal sewer system. Their removal efficiencies in primary sedimentation tank of municipal WWTP were very low. From the practical point of view, the highest and the most significant removal efficiencies within the whole WWTP were observed for nonylphenol and nonylphenol ethoxylates. Dominancy of abiotic mechanisms of alkylphenols removal follows from adsorption measurements. Activated sludge cultivated in lab-scale extended aeration tank accounted for relatively high adsorption affinity to these substances. Activated sludge sampled from municipal wastewater treatment plant (MWWTP) receiving industrial wastewater containing alkylphenols accounted for very low adsorption affinity to these pollutants. Significantly higher removal efficiency of octylphenol ethoxylates was observed with the $\mathrm{O}_{3}$ /granular active carbon (GAC) process compared to the ozonation process alone. Lower toxicity impact of intermediates and products of ozonation treatment on Vibrio fischeri was measured in comparison to the $\mathrm{O}_{3} / \mathrm{GAC}$ process. Actually, the municipal WWTP effluent discharge concentration values complies with EQS values, including nonylphenols.
\end{abstract}

Key words:

alkylphenols, industrial and municipal wastewater treatment, ozonation, $\mathrm{O}_{3} / \mathrm{GAC}$, priority substances, toxicity

\section{Introduction}

Alkylphenols (APs) are used as antioxidants and plasticizers, and also in the production of alkylphenol ethoxylates (APEOs). Approximately $80 \%$ of all APEOs production is released to the market as nonylphenol ethoxylates (NPEOs) ${ }^{1}$, which are widely used in the production of plastics, textiles, and agricultural chemicals, and in household goods such as detergents, paints, pesticides, and cosmetics. These consist of a very complex mixture of isomers $^{2}$. Nonylphenol is used as antioxidant, in plastic additives, and mainly for synthesizing NPEOs as non-ionic surfactants in detergents, emulsifying agents, pesticide formulations, herbicides, and dispersing agents in the paper and pulp industry.

Nonylphenol polyethoxylates are degraded primarily to the corresponding nonylphenols (NPs), and thus are ubiquitous in the environment. Nonylphenol polyethoxylates are oxidised to NPs under anaerobic conditions (i.e. in sewer system, sedi-

${ }^{*}$ Corresponding author: e-mail: jan.derco@stuba.sk, tel.: +421904 171 ments and during anaerobic processes at WWTP), they are known to be unstable and toxic in water environments, and exhibit estrogenic activities ${ }^{3}$. Nonylphenol polyethoxylates are transformed by microorganisms to more toxic compounds, e.g. NP and NPEOs with shorter chains ${ }^{4}$. Nonylphenol and nonylphenyl ethoxylates are designed as priority hazardous substances in Water Framework Directive $^{5}$ and most of their use is currently regulated by Directive 2003/53/EC ${ }^{6,7}$. Accordingly, a large majority of the research related to APEOs and APs destruction in the water environment is focused on $\mathrm{NP}$, which enter the environment through wastewater streams with NPEOs.

Gültekin and Ince $^{3}$ published an overview of Advanced Oxidation Processes (AOP) applied for the removal of endocrine disruptors from water environments. NPs often occur in wastewater as degradation product of NPEOs ${ }^{7}$. The principal pathway for nonylphenol removal in wastewater treatment plants is sorption to the sludge solids ${ }^{8}$. Ning et al. ${ }^{9}$ investigated the destruction of 4-tert-octylphenol (OP) and NP by direct reaction with ozone (ozono- 
lysis). They found that ozone reacts easily with both alkylphenols. Tertial ozonation contributed also to the decrease of water estrogenic activity ${ }^{10}$. The advantage of AOPs over all chemical and biological processes is that they are environmentally friendly.

Ozone may react with organic compounds in two ways: by direct reaction as molecular ozone or by indirect reaction through formation of secondary oxidants like free radical species ${ }^{11-13}$. In practice, both mechanisms may occur, depending on the type of chemical wastewater pollution. At low $\mathrm{pH}$, the predominant reaction mechanism is the direct electrophilic attack by molecular ozone ${ }^{14}$. Molecular ozone is a rather selective oxidant. It can react directly with certain functional groups of organic compounds found in water and wastewaters, such as unsaturated and aromatic hydrocarbons with substitutes such as hydroxyl, methyl and amine groups, giving rise to degradation products. Because of this high selectivity, many industrial wastewater treatment oxidations can be performed with molecular ozone. On the other hand, ozone decomposes in water to form $\bullet \mathrm{OH}$, which are stronger oxidizing agents than ozone itself, thus inducing so-called indirect ozonation. Indirect ozone oxidation is non-selective and is favoured at alkaline $\mathrm{pH}$ conditions. Ozone decomposition in water can be initiated by the hydroxyl anion, HO-. Treatment performance is enhanced if ozone is combined with ultraviolet irradiation, hydrogen peroxide or with iron or copper complexes that act as catalysts, thus generating additional $\bullet \mathrm{OH}$.
The main aim of our preliminary study was to investigate removal of NP, OP and their ethoxylates from a real industrial and municipal WW. Industrial wastewater dealing with these APs was pre-treated by coagulation with $\mathrm{FeCl}_{3}$ and adsorption on zeolite (ZEO), before discharging into municipal sewer system. Another objective of the work was to investigate an alternative WW treatment process in a case of extended production and related consequent increase of alkylphenols release. Evaluation of municipal WWTP capacity located closest to the industrial plant discharging alkylphenols, including alternative tertiary process treatment of municipal wastewater, were another goal. Biotic and abiotic removal processes with activated sludge, adsorption on granular activated carbon (GAC), ozonation and combined $\mathrm{O}_{3} / \mathrm{GAC}$ processes were investigated.

\section{Materials and methods}

Fig. 1 shows the lab-scale jet loop ozonation equipment. The ozonation reactor was $0.08 \mathrm{~m}$ in diameter and $1.0 \mathrm{~m}$ in height. Effective volume of the reactor was 3.5 L. External circulation of the reaction mixture was maintained at $0.5 \mathrm{~L} \mathrm{~min}^{-1}$ by a membrane pump. The Lifetech ozone generator with the maximum ozone production of $5 \mathrm{~g} \mathrm{~h}^{-1}$ was used. Ozone was prepared from pure oxygen. Ozone generator was operated at $80 \%$ of the maximum power. Oxygen flow $60 \mathrm{~L} \mathrm{~h}^{-1}$ and external recirculation flow $50 \mathrm{~L} \mathrm{~h}^{-1}$ were maintained during ozonation trials performance. The oxygen flow was measured by a flow meter, placed at the inlet of oxygen into the ozone generator.

The ejector represents a specific part of this ozonation reactor from the point of view of the gas-to-water phase transfer of ozone and the reaction conditions. The mixture of $\mathrm{O}_{3}$ and $\mathrm{O}_{2}$ was injected into a wastewater sample through a Venturi ejector. At the same time, the ejector sucked the mixture of $\mathrm{O}_{3}$ and $\mathrm{O}_{2}$ from the reactor headspace. This, together with external circulation, should improve efficiency of ozone utilization in the ozonation reactor. Concentration of ozone in the gas phase at the inlet and outlet of the reactor was measured using a laboratory scale Life ODU 200 UV detector. The amount of ozone transferred from the gas to the liquid phase in the reactor during the ozonation process was evaluated using the mass bal-
Fig. 1 - Schematic diagram of the experimental apparatus

1 - oxygen, 2 - ozone generator, $3-\mathrm{O}_{2}$ and $\mathrm{O}_{3}$ mixture, 4 - ozone detector, 5 - ozonation reactor, 6 - Venturi ejector, 7 - UV lamp, 8 - reactor tempering, 9 - pump, 10 - external liquid recirculation, 11 - head space gas recirculation, 12 - sampler, 13 - outlet gas mixture, 14 - bubble column for residual ozone destruction 
ance based on the inlet and outlet concentrations of ozone in the gas phase.

The destruction of excess ozone was performed in bubble column filled with a solution of potassium iodide. The bubble column was $0.04 \mathrm{~m}$ in diameter and $1.7 \mathrm{~m}$ in height. The effective volume of the bubble column was $1.0 \mathrm{~L}$. The system was operated in batch mode with regard to wastewater samples. The samples were added into a jet loop ozonation reactor at the beginning of the trials.

\section{Applied analytical methods}

The group of 4-nonylphenols, 4-tert-octylphenol and their ethoxylates were monitored in wastewater samples $(0.5 \mathrm{~L})$ using liquid-liquid extraction with $0.01 \mathrm{dm}^{3}$ of n-hexane and HPLC method equipped with a column LiChrosphere with stationary phase $\mathrm{C} 18,12.5 \mathrm{~cm} \times 4.0 \mathrm{~mm}, 5.0 \mathrm{~mm}$ and fluorescence detector (Agilent Technologies 1200). Excitation and emission energies were set on 232 and $310 \mathrm{~nm}$. Method using gradient elution with two mobile phases of methanol as mobile phase A and acetonitrile to water $=5: 95(\mathrm{v} / \mathrm{v})$ as mobile phase $\mathrm{B}$ according to Table 1, delivered at a flow rate from 0.1 to $1.0 \mathrm{dm}^{3} \mathrm{~min}^{-1}$. The results were evaluated on external calibration with range $0.05-0.80 \mathrm{mg} \mathrm{L}^{-1}$ and correlation coefficients higher than 0.999. Limit of detection was $0.011 \mathrm{mg} \mathrm{L}^{-1}$. The uncertainty of measurement was between $15-18 \%$.

\section{Experimental}

Schematic of sampling points is shown in Fig. 2. The measurements were performed with samples of the real industrial wastewater containing alkylphenols. The wastewater was pre-treated by physicochemical processes in industrial WWTP (sampling point SP1) before discharging it into the public sewer system, and then fed into the municipal sewage treatment plant. Further experiments were performed with the samples of wastewater from the inlet (SP2) and/outlet (SP3) of mechanical

Table 1 - Gradient of mobile phase

\begin{tabular}{c|c|c}
\hline Time (min) & $\%$ B & $\begin{array}{c}\text { Flow } \\
\left(10^{3} \mathrm{~L} \mathrm{~min}^{-1}\right)\end{array}$ \\
\hline 0 & 40 & 0.1 \\
1 & 40 & 1.0 \\
21 & 17 & 1.0 \\
22 & 40 & 1.0 \\
23 & 40 & 1.0 \\
24 & 40 & 0.1 \\
\hline
\end{tabular}

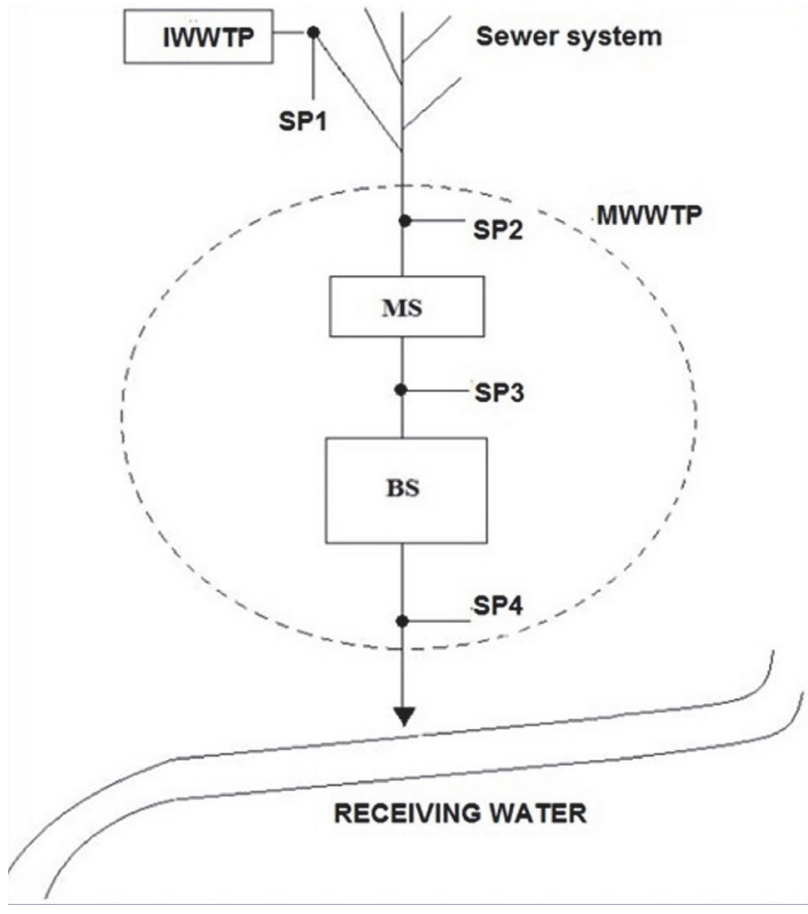

Fig. 2 - Schematic of sampling points

stage (MS), and, at the same time, at inlet of biological stage (BS) of municipal WWTP and from the outlet of this WWTP (SP4).

\section{Results and discussion}

The results from two independent monitorings of APs behaviour at individual stages in the MWWTP are presented in Fig. 3 in dimensionless concentrations. Dimensionless concentrations are the concentration values of monitored variables, which are relative to the concentration values of individual variables measured in an influent wastewater, i.e. the values divided by the concentration values contained in the influent wastewater.

Removal efficiencies of investigated APs and APEOs in parallel primary sedimentation tanks PST_1 and PST_2 were very low.

From the practical point of view, the highest and the most significant removal efficiencies within the whole WWTP (effluent from secondary sedimentation tank SST) were observed for NP (removal efficiencies from 82.9 to $93.5 \%$ ) and NPEOs (removal efficiencies from 6.5 to $82.1 \%$ ). Removal efficiencies for other studied substances were lower than $25.0 \%$.

Dominancy of abiotic mechanisms of APs removal follows from adsorption measurements. Activated sludge cultivated in lab-scale extended aeration tank accounted for relatively high adsorption affinity to APs and APEOs contained in an industri- 


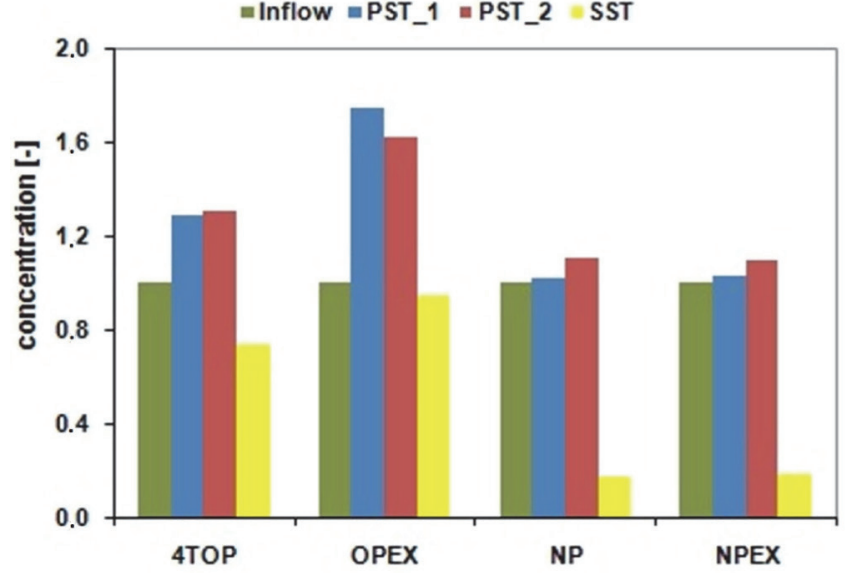

Fig. 3 - Changes in APs content in MWWTP

al WW (Fig. 4). The removal efficiencies were in the range from $34.7 \%$ (OP) to $94.9 \%$ (NPEOs).

Based on the previous observations, i.e. the highest removal efficiencies occurred in secondary sedimentation tank, we performed adsorption tests with discharged industrial WW and activated sludge sampled from a MWWTP, and excess sludge sampled from lab-scale model of extended aeration process. As may be seen from Fig. 4, activated sludge sampled from the municipal WWTP receiving industrial WW with a content of APs accounted for very low adsorption affinity to these substances. The highest removal efficiency, $33.0 \%$, was observed for NP. The axis on the right is valid for the variable labelled by arrow, i.e. for OPEX and NPEX in the case of Fig. 4.

On the other hand, activated sludge cultivated in lab-scale extended aeration tank accounted for relatively high adsorption affinity to alkylphenols (Fig. 5). The removal efficiencies were in the range from $34.7 \%$ (4TOP) to $94.9 \%$ (NPEX).

Ozone selectivity of the examined APs and their ethoxylates depends on a WW composition. Higher removal rates of APs and treatment efficiencies by ozone were observed in the case of industrial WW. The highest removal efficiencies of NP and NPEOs were measured during ozonation of industrial WW (Fig. 6). The mean values of removal efficiency varied from $6.2 \%$ for NPEX to $98.2 \%$ in the case of OPEX. The highest removal efficiencies (over $98 \%$ ) were observed for OPEX. Nonylphenol ethoxylates showed the highest variability of the removal efficiency values (3.0-92.7 \%). The lowest and relatively stable values of treatment efficiency are characteristic for the 4-tert-octylphenol (10.2$22.1 \%)$.

Ozonation of MWWTP effluent discharge resulted in low residual APs and APEOs concentrations (Fig. 7). Mean values of treatment efficiencies in the range from $3.3 \%$ (OPEX) to $83.2 \%(\mathrm{OP})$

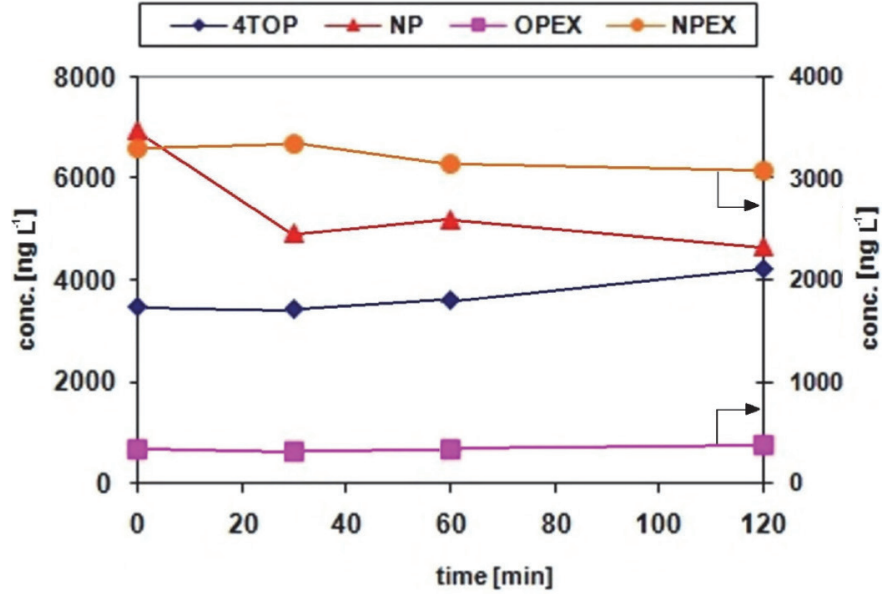

Fig. 4 - Adsorption of APs on excess sludge sampled at municipal WWTP

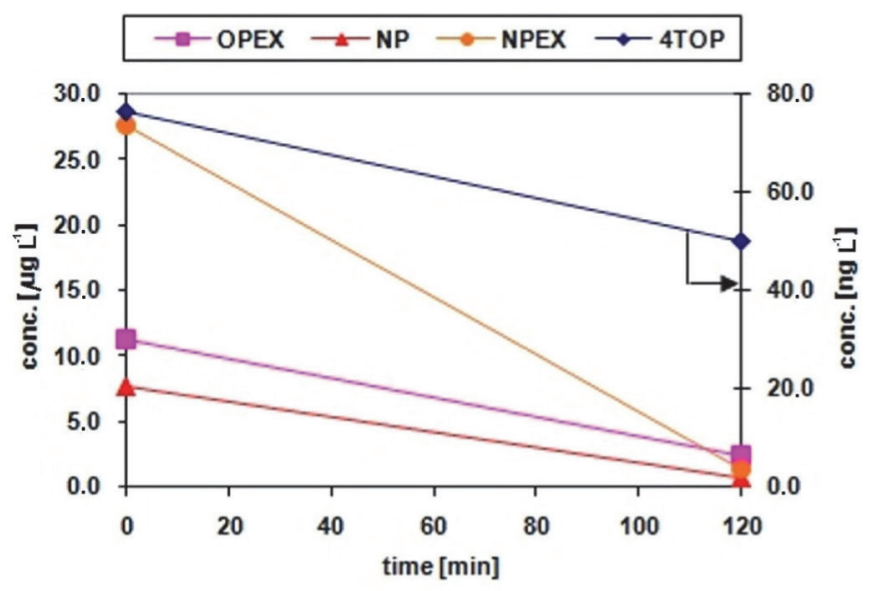

Fig. 5 - Adsorption of APs on excess sludge from lab-scale extended aeration

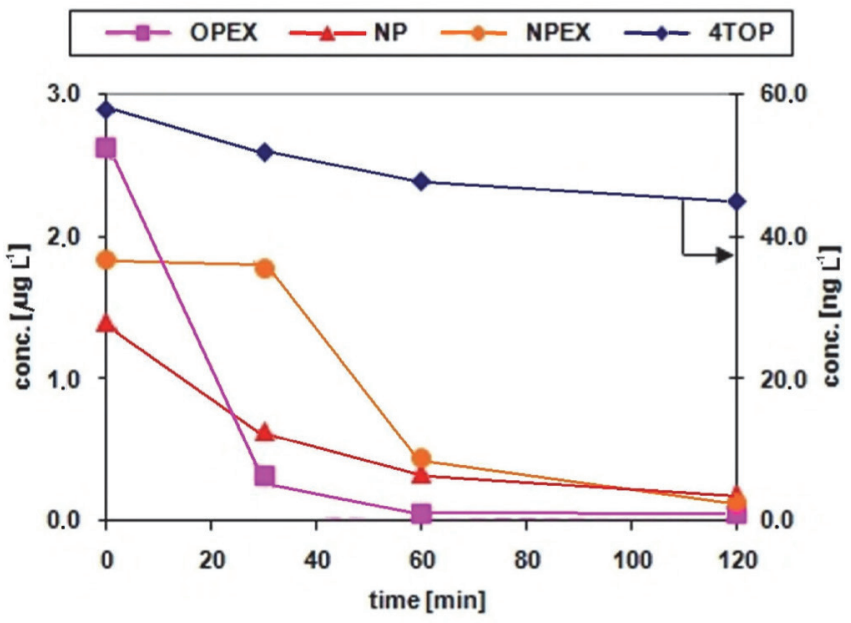

Fig. 6 - Ozonation of an industrial WWTP effluent discharge

were observed during ozonation of municipal WW after receiving an industrial WW with APs content. The highest removal efficiency, $92.7 \%$, was observed for nonylphenol ethoxylates. Similar remov- 


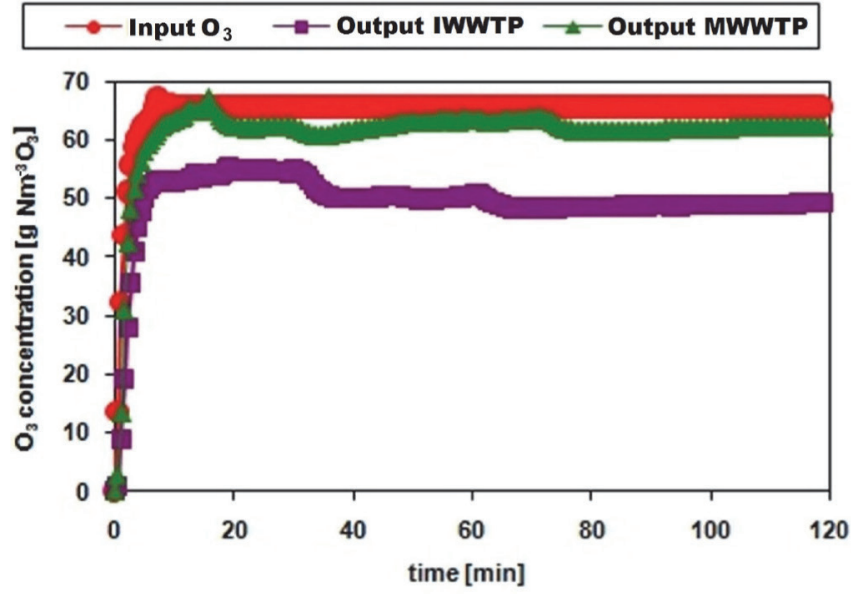

Fig. 7 - Ozonation of an industrial WWTP effluent discharge

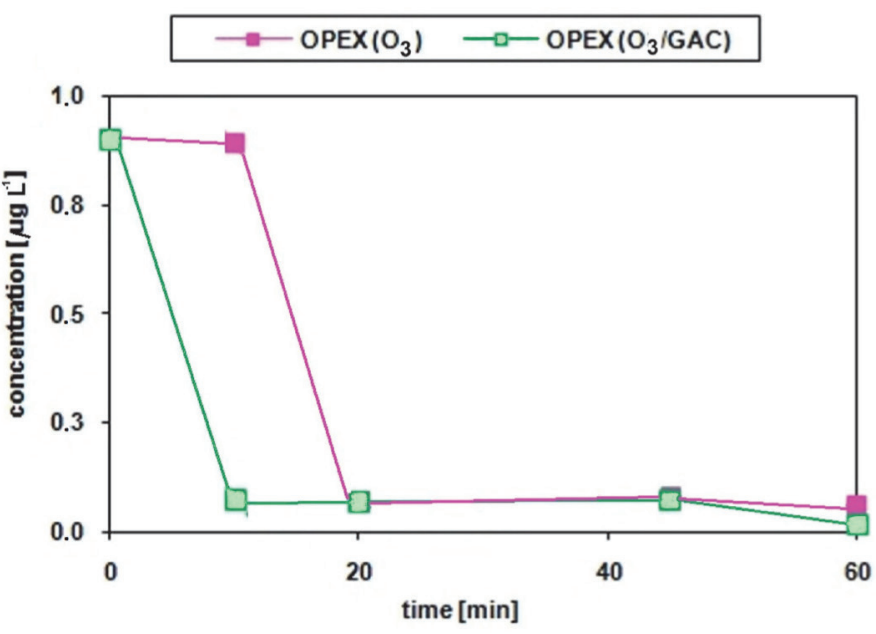

Fig. 9 - Treatment of effluent from municipal WWTP by $\mathrm{O}_{3}$ and $O_{3} / G A C$

al rates of OP and their ethoxylates were published by Ning et al. ${ }^{9}$ based on results of single component (NP, NPEOs). The most stable values of treatment efficiency are characteristic for the OP $(82.2-84.7$ $\%)$. The lowest and relatively stable values of treatment efficiency are typical for the octylphenol ethoxylates (0-6.5\%) and 4-nonyl phenol (10.4 $17.0 \%)$.

High variability in treatment efficiency during ozonation of both municipal and industrial WW were observed when treating WW samples taken in different time (mean values $70.5 \%$ for NP and 48.9 $\%$ for NPEOs).

Significantly higher volumetric ozone consumption was observed for industrial WW treatment in comparison with municipal WW ozonation (Fig. 8), due to higher organic pollution.

Fig. 9 shows the time courses of removal/ transformation OPEX during the ozonation and combined $\mathrm{O}_{3} / \mathrm{GAC}$ process. From a comparison of

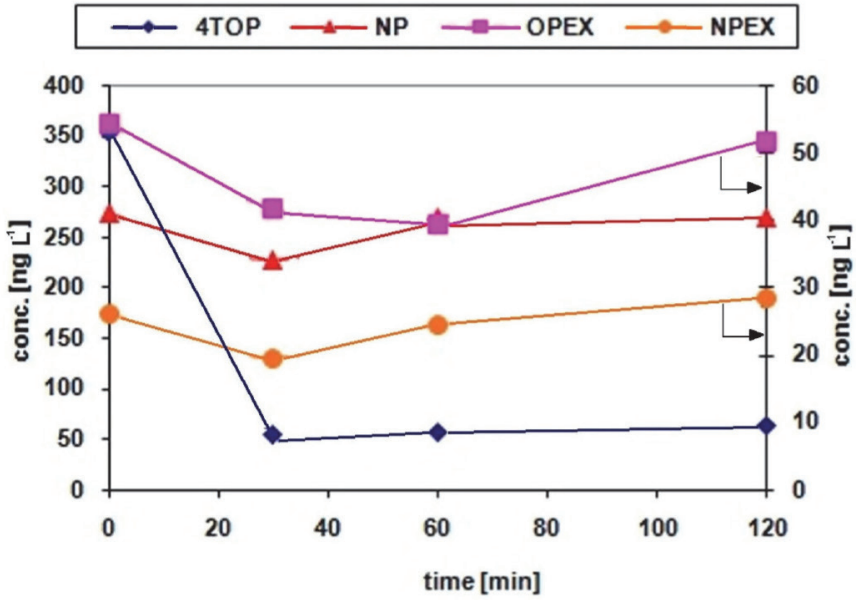

Fig. 8 - Ozone consumption during ozonation of industrial and municipal WWTP effluent discharges

these time dependencies follows higher removal/ transformation rate of OPEX by combined $\mathrm{O}_{3} / \mathrm{GAC}$ process, and in particular, about two times faster onset of this process compared with the very ozonation. The other components were removed in the first 10 minutes.

Significantly higher removal efficiency of octylphenol ethoxylates was observed with the $\mathrm{O}_{3} /$ GAC process compared to the ozonation process alone. It can be concluded that removal of NPs from industrial WW before its discharging to the municipal sewer system is not required. Actually, the municipal WWTP effluent concentrations comply with effluent quality standard (EQS) values, including NPs.

\section{Conclusion}

The highest removal efficiencies of nonylphenols and their ethoxylates were observed in the secondary settling tank of the municipal WWTP. The highest adsorption removal efficiencies of nonylphenols and their ethoxylates were measured with the activated sludge cultivated in lab-scale bioreactor operated as extended aeration. Activated sludge sampled at the municipal WWTP receiving industrial wastewater containing alkylphenols proved very low adsorption affinity to investigated alkylphenols. Higher alkylphenols removal rates and treatment efficiencies with ozone were observed in the case of industrial WW. However, high variability in treatment efficiency during ozonation of municipal as well as industrial WW was observed. Higher rate of transformation and removal of octyphenol ethoxylates, and about a twice-faster onset of the $\mathrm{O}_{3} / \mathrm{GAC}$ process was observed in comparison with the very ozonation. The other components were removed in the first 10 minutes. Nonylphenol and nonylphenol 
ethoxylates residual concentrations in all analyzed samples of municipal WW complied with the limits of Environmental Quality Standards.

\section{ACKNOWLEDGEMENTS}

This work was supported by the Slovak Research and Development Agency under the contract No. APVV-0656-12. The authors are thankful for the support of the VEGA Grant 1/0859/14.

\section{References}

1. Ying, G. G., Williams, B., Kookana, R., Environmental fate of alkylphenols and alkylphenol ethoxylates, A review, Environ. Int. 28 (2002) 215. doi: https://doi.org/10.1016/S0160-4120(02)00017-X

2. Boehme, R. M., Andries, T., Dötz, K. H., Thiele, B., Guenther, $K$., Synthesis of defined endocrine-disrupting nonylphenol isomers for biological and environmental studies, Chemosphere 80 (2010) 813. doi: https://doi.org/10.1016/j.chemosphere.2010.03.064

3. Gültekin, I., Ince, N. H., Synthetic endocrine disruptors in the environment and water remediation by advanced oxidation process, Journal of Environmental Management $\mathbf{8 5}$ (2007) 816. doi: https://doi.org/10.1016/j.jenvman.2007.07.020.

4. Vazquez-Duhalt, R., Marquez-Rocha, F., Ponce, E., Licea, A. F., Viana, M. T., Nonylphenol, an integrated vision of a pollutant, Applied Ecology and Environmental Research 4 (2005) 1.

5. Directive 2000/60/EC of the European Parliament and of The Council of 23 October 2000 establishing a framework for community action in the field of water policy, Off. $J$. Eur. Communities, L 327/1 (2000).

6. Directive 2003/53/EC of the European Parliament and of the Council of 18 June 2003 amending for the 26th time Council Directive 76/769/EEC relating to restrictions on the marketing and use of certain dangerous substances and preparations (nonylphenol, nonylphenol ethoxylate and cement), 2003. Off. J. Eur. Union, OJ L 46 (2003) 24-27.
7. Soarez, A., Guieysse, B., Jefferson, B., Cartmel, E., Lester, $J$. $N$., Nonylphenol in the environment: A critical review on occurrence, fate, toxicity and treatment in wastewaters, Environmental Int. 34 (2008) 1033. doi: https://doi.org/10.1016/j.envint.2008.01.004

8. Shao, B., Hu, J., Yang, M., Nonylphenol ethoxylates and their biodegradation intermediates in water and sludge of a sewage treatment plant, Bull Environ. Contam. Toxicol. 70 (2003) 527. doi: https://doi.org/10.1007/s00128-003-0018-0.

9. Ning, B., Graham, N. J. D., Zhang, Y., Degradation of octylphenol and nonylphenol by ozone - Part I: Direct reaction, Chemosphere (2007) 68. doi: https://doi.org/10.1016/j.chemosphere.2007.01.055

10. Bertanza, G., Pedrazani, R., Dal Grande, M., Papa, M., Zambarda, V., Mantani, C., Steimberg, N., Mazzoleni, G., Di Lorenzo, D., Effect of biological and chemical oxidation on the removal of estrogenic compounds (NP and BPA) from wastewater: An integrated assessment procedure, Wat. Res. 45 (2011) 2473 doi: https://doi.org/10.1016/j.watres.2011.01.026

11. Hoigné, J., Bader, H., Rate constants of reactions of ozone with organic and inorganic compounds in water. I. Non-dissociating organic compounds, Wat. Res. 17 (1983) 173. doi: https://doi.org/10.1016/0043-1354(83)90098-2

12. Arslan-Alaton, I., The effect of pre-ozonation on the biocompatibility of reactive dye hydrolysates, Chemosphere 51 (2003) 825. doi: https://doi.org/10.1016/S0045-6535(03)00231-5

13. Sánchez-Polo, M., Rivera-Utrilla, J., Prados-Joya, G., Ferro-García, M. A., Bautista-Toledo, I., Removal of pharmaceutical compounds, nitroimidazoles, from waters by using the ozone/carbon system, Wat. Res. 42 (2008) 4163. doi: https://doi.org/10.1016/j.watres.2008.05.034

14. Directive 2008/105/EC of the European Parliament and of the Council of 16 December 2008 on environmental quality standards in the field of water policy, amending and subsequently repealing Council Directives 82/176/EEC, 83/513/ EEC, 84/156/EEC, 84/491/EEC, 86/280/EEC and amending Directive 2000/60/EC (2008).

15. Directive 2013/39/EC of the European Parliament and of The Council of 12 August 2013 amending Directives 2000/60/EC and 2008/105/EC as regards priority substances in the field of water policy, Off. J. Eur. Union, L 226/1 (2013). 